\title{
Phase change memory: Operation, current challenges and future prospects
}

\author{
Pooja Gupta $^{1}$, Pooja Lohia ${ }^{2}$, D.K. Dwivedi ${ }^{3}$ \\ ${ }^{I^{*}}$ Department of Physics and Material Science, Madan Mohan Malaviya University of Technology, INDIA \\ ${ }^{2}$ Department of Electronics and communication, Madan Mohan Malaviya University of Technology, INDIA \\ ${ }^{3}$ Department of Physics and Material Science, Madan Mohan Malaviya University of Technology, INDIA \\ *Corresponding Author: e-mail:pg54896@gmail.com \\ ORCID iD: https://orcid.org/0000-0002-8334-5535
}

\begin{abstract}
Phase change memory has become known and most advanced resistive memory technology to meet the consumer's applications. It is a non-volatile random access memory. It plays a vital role in order to overcome the increasing demand of powerful data storage devices. In the present paper, advantages over other memories have been discussed in detail. This review focuses on the device operation of PCM. The current challenges and future prospects have also been outlined.
\end{abstract}

Keywords: Phase change memory, phase change materials, set and reset, PCM lance cell, Non-volatile memory, Ovonic Threshold Switching.

DOI: http://dx.doi.org/10.4314/ijest.v13i1.14S

Cite this article as:

Gupta P., Lohia P., Dwivedi D.K. 2021. Phase change memory: Operation, current challenges and future prospects. International Journal of Engineering, Science and Technology, Vol. 13, No. 1, pp. 93-97. doi: 10.4314/ijest.v13i1.14S

Received: December 1, 2019; Accepted: February 5, 2021; Final acceptance in revised form: March 31, 2021

This paper was earlier presented at the International Conference on Energy, Environment \& Material Sciences (ICE2M), 1-3 December 2019 and substantially improved for this Special Issue. Guest Editor: Dr. Sri Niwas Singh, Professor (HAG), Department of Electrical Engineering, Indian Institute of Technology Kanpur, 208016 (U.P.) India, former Vice-Chancellor, Madan Mohan Malviya University of Technology Gorakhpur (April 2017 to July 2020).

\section{Introduction}

In the present era, the electronic appliances are widely used. Semiconductors emerge as the heart of the modern electronic world. It is widely used from digital watches to super computers. The modern information society is marked by fast increasing demand for effective data storage devices, which results into the innovative storage concepts. The capability of humankind to conserve knowledge has been a salient feature of man development. Books can't store more information while huge amount of data can stored in USB Flash Drives, Floppy disk, DVD and semiconductor chips[1].Non -volatile storage technologies play a basic involvement in microelectronic industry. Till now, more than thirty known Non-volatile memory technologies have been participating to enter in steady increasing NVM market[2].The steadily increasing use of digital watches, android phones, MP3 players asserts in enhancement of memory strength and features. However, CD can store $700 \mathrm{MB}$ of data, DVDs can store upto 8.4GB of data, Blu-ray disc can store 50GB of data[3]. HVDs are expected to store data in TBs..

Phase Change Memory is such a memory which can store more data than that of CDs, DVDs, Blu-ray etc within the same area[4]. PCM is a combination of Flash and DRAM. As it has higher latency, higher density, higher endurance, low power consumption, fast operation speed, it has been participating to enter in the steady growing Non-volatile market and emerging as storage class memory (SCM)[5].In this memory, data can be read and write even when power goes off. Phase transition phenomenon occurs to store information. Recently IBM researchers have presented a PCM chip that can store three bits per 
cell[4].

The first part of review has been focussed on comparison of Phase change memory with various memories which clarifies that PCM is an emerging technology. In the second part of review, PCM lance cell and Phase Change materials have been discussed. Recent developments on PCM, current challenges and future prospects are discussed in last section.

\section{Comparison of PCM with other memories}

The recent memory technologies have a great extent of circumstances. DRAMs, Flash memory, SRAM, EPROMs, etc have many limitations such as SRAMs are much expensive ,EPROMs require high power and have poor flexibility [6-7].There is difficult to integrate DRAM[8]. Comparison of PCM with other memory as shown in table 1. So to maintain the forthcoming market of wireless and portable gadgets,a higher performance at lower price is required. Ovonic Threshold Switching is an optimistic device to meet this need.Phase change memory operates in a picosecond timescale,that's why they are faster than flash memory[9]. The high density of OUM results into the storage of multiple bits of information within a small area. Fast operation speed,better endurance,low power consumption make it a powerful data storage device.PCM is anon-volatile RAM that employs the chalcogenide materials for storage of binary data[10]. In this paper,we focused on one of the most prominent memory technology -Chalcogenide RAM, with a focus on their device operation.

Table 1. Comparison of PCM with other memories

\begin{tabular}{|l|l|l|l|l|l|}
\hline Attributes & PCM & EPROM & NOR & NAND & DRAM \\
\hline Software & Easy & Easy & Moderate & Hard & Easy \\
\hline Read latency & $50-100 \mathrm{~ns}$ & $200 \mathrm{~ns}$ & $70-100 \mathrm{~ns}$ & $15-50 \mu \mathrm{s}$ & $20-80 \mathrm{~ns}$ \\
\hline Write bandwidth & $1-15+\mathrm{MB} / \mathrm{s}$ & $13-30 \mathrm{kB} / \mathrm{s}$ & $0.5-2 \mathrm{MB} / \mathrm{s}$ & $10+\mathrm{MB} / \mathrm{s}$ & $100+\mathrm{MB} / \mathrm{s}$ \\
\hline Erase & No & No & Yes & Yes & No \\
\hline Non-volatile & Yes & Es & Yes & Yes & No \\
\hline Endurance & $10^{8+}$ & $10^{5}-10^{8}$ & $10^{5}$ & $10^{4-5}$ & Unlimited \\
\hline Granularity & Small/Byte & Small/Byte & Large & Large & Small/Byte \\
\hline
\end{tabular}

\section{Modelling and device function}

PCM contains PCM lance cell that includes mainly phase change materials, metal electrode,resistive plug,transistor. As manufactured, the material is in high conductance state. It is because the action temperature of the metal linked layers is abundant to crystallize. At beginning, programming region is melted then a large electrical current pulse applied for a short duration to quench it into amorphous state. Then, a region of amorphous stain material is formed in PCM cell. This amorphous region is in sequence with low resistance state of PCM and successfully governs the resistance of memory cell between the top electrode and lower electrode.

An electrical pulse or laser pulse is applied to temper the active region at a temperature between the crystallization temperature and the melting temperature for a long duration to get back crystalline state. To read the state of programming region, cell resistance is determined by applying an electrical current [11].The mobile phase change material is intermediate between heater and top electrode.Fig 1 shows PCM Lance Cell and SET and RESET Pulse. When an electrical pulse or laser pulse is applied to the PCM lance cell,the joule heating of mushroom shaped volume of materials occurs. When there is a change of phase from amorphous to crystalline, then SET Pulse is achieved which corresponds to logic ' 1 '. RESET pulse is achieved when state changes from crystalline to amorphous and that corresponds to logic ' 0 ' [12] given to cell not by energy imparted to cell.

RESET resistance is affected by pulse current amplitude. The important characteristic of phase change memory is Ovonic Threshold Switching. The electrical resistance of two phases differs in magnitude. On applying electrical pulse, as the bias reaches a certain voltage Vth, there is a drastic and sudden change from low conductance to high conductance which results into ovonic threshold switching phenomenon[11-12]. The set process is dependent on ovonic threshold switching. On applying electric field across the amorphous region, approaching the threshold value, conductance of the amorphous region increases. This ovonic threshold switching phenomenon, is prime to successful set action of the memory. The ovonic threshold switching effect raise the conductance of these materials to the dynamic resistance and authorize set programming. The thermal conductivity, the device structure and resistivity governs the reset current. Basically, the functioning speed of PCM is governed by set action time as it takes limited time to change amorphous region into crystalline region. 


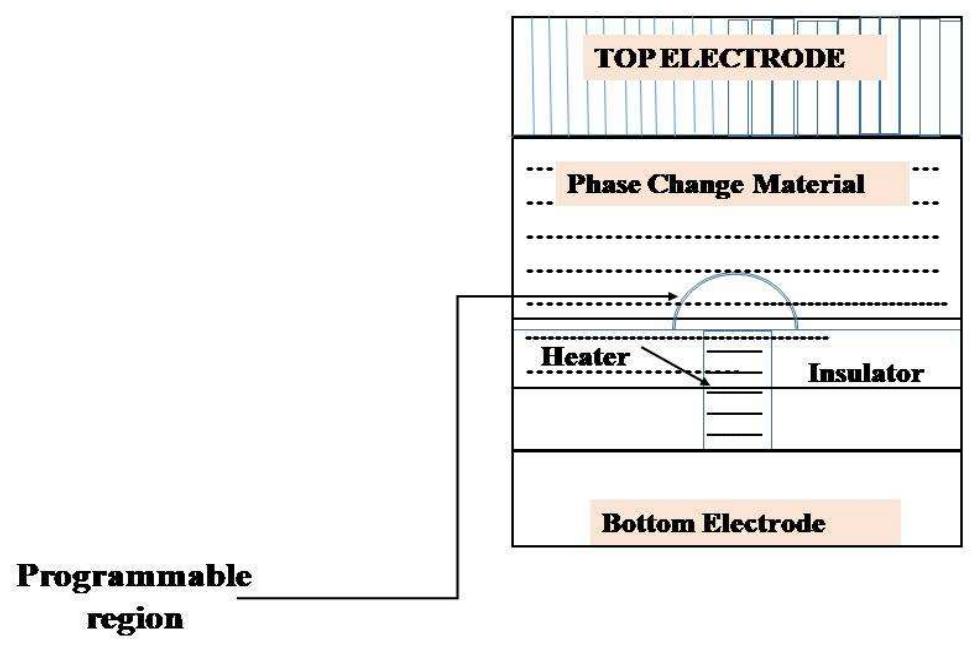

Figure 1. PCM lance cell

\section{Phase change materials}

To store the binary data, OUM devices uses chalcogenide materials. The semiconducting glasses made using VI group elements of periodic table are chalcogenides[13]. In optical recording techniques, the chalcogenide glasses which have characteristic property of phase transition perform a keyrole[14]. PCM employs the orders of magnitude large difference between the conductivity of amorphous and crystalline phase in these materials[15]. The two different solid phases of materials are amorphous and crystalline. Due to differences in their structure, they have distinct electrical and optical properties[16]. These distinct properties can be considered to store information in technological practice. To prepare amorphous stain, a pulsed sharp laser beam is applied for a short time. Thereafter, the temperature of phase change layer becomes higher than melting point. On removing pulse, the liquefied region is quenched to the amorphous state. The written mark can be read out by studying the difference in the reflectance.

Binary compound Ge-Te is such a phase change material that has good thermal stability than Ge-Sb-Tl based PCM material[15] and also reduces energy consumption[17].GeTe dopped with carbon is a novel phase change material as it provides both good data retention and also good programming characteristics[18]. $\mathrm{Se}_{82-\mathrm{x}} \mathrm{Te}_{18} \mathrm{Sb}_{\mathrm{x}}(\mathrm{x}=0,4,8,12)$ based phase change material allows low thermal conductivity, low melting point[19]. On increasing $\mathrm{Sb}$ to Se-Te system ,activation energy and glass transition temperature increases. This is favourable for making memory with good characteristics. Ternary compound such $\mathrm{as} \mathrm{Ge}_{2} \mathrm{Sb}_{2} \mathrm{Te}_{5}$ is widely used in DVDs and $\mathrm{Ge}_{8} \mathrm{Sb}_{2} \mathrm{Te}_{11}$ in Blu-ray discs. Now-a-days, the structure of CDs, DVDs, Blu-ray disc remains same as the earlier ones, only the variation occurs in thickness and composition of phase change material. Carbon nanotubes based material gives boost to latent energy storage[20]. Recently neural network based phase change material are fabricated to enhance memory performances[21]. Quarternary compounds based materials are becoming new trends for the storage of data in memory.

\section{Current challenges and future prospects}

The challenges include the reduction of heating in the PCM lance cell. More heating may cause damage to PCM lance cell. Suitable phase change materials are required so as to increase the rate of crystallization and amorphization. Reduction in SET and RESET current is needed. Synthesis of these materials is still a challenge. These materials should have economical manufacturing process. Many more companies are looking forward for MLC(Multilevel cell) for PCM. However, even though vastly optimistic, C-RAM needs to enhance its cost-effectiveness as compared to DRAM, NAND, SRAM and Flash. Furthermore, the feasibility of expanding new compulsive application PCM-based has not been seriously displayed yet.

Researchers suggest that phase change materials can be scaled to nanometer sizes that exhibit same phase change behaviour[22]. Manufactures focus on composite electrode and advanced phase change material to enhance the thermal efficiency of devices[22].Challenge is to reduce the device size so as to minimize power consumption. However, there is need to innovate fast switching materials so as to increase data rate to achieve a memory device, capable of non-volatile operations beyond gigahertz data-transfer rates. 


\section{Conclusion}

In the present paper, the recent developments of phase change memory have been outlined. Phase change memory offer several important properties for high endurance, fast operation speed, data retention characteristics, high density. Because of the features of PCM, many industries are looking forward to Ovonic Unified Memory that might replace flash memory. It is potentially competitive with volatile memory technologies. Current challenges and future prospects of PCM have also been discussed. The principal aim of today PCM developers is to increase the density of memory and decrease energy and power utilization. Another prime feature is the enhancement of data retention property to label embedded memory application. A prime feature for OUM success, is as apparent the evolution of definitive, good-controlled fabricating process. To achieve such ambitious goals, latest PCM materials is expected to be developed in coming days.

\section{Acknowledgement}

We are sincerely grateful to the referees for their valuable comments which have helped in improving the overall clarity and readability of this article.

\section{References}

Anam, M.K. Ahn E.C., 2017, Understanding the effect of dry etching on nanoscale Phase change memory, IOP Science, $4374-$ 4385. DOI:10.1088/1361-6528/ab4079

Beneventi G.B., Sousa V., Pernida L., Gourvest E., 2011, Carbon-doped GeTe: A promising material for phase change memory, Solid State Electronics, pp. 197-204. DOI:10.1016/j.sse.2011.06.029

Bruns G., Merkelbach P., Schlockermann C., Salinga M., Wuttig M., 2009, Nanosecond switching in GeTe phase change memory cells, Applied Physics Letter, Vol 95, No. 4. DOI:10.1063/1.3191670

Choi H.J., Oh S.J., Jung D., 2015, Storage device based on a flash memory and user device including the same, US Patent 9, Vol. 032, 138.

Hudgens S., Johnson B., 2004, Overview of Phase change chalcogenide Non volatile Memory Technology, IEEE, Vol. 29, No. 11, pp. 829-832. DOI:10.1557/mrs2004.236

Lankhorst M.H.R., Katelaars B.W.S.M.M., Wolters R.A.M., 2005, How cost and nanoscale non volatile memory concept for future silicon chips, Nature Material, Vol 4, pp. 347-352. DOI:10.1038/nmat1350

Nazir H., Batool M., Bolivar Osorio F.J., Ruiz M.I., Xu X., 2019, Recent developments in phase change materials for energy storage applications, International Journal of Heat and Mass Transfer, Vol 129, pp. 491-523. DOI:j.jheatmasstransfer.2018.09.126

Pan F., Gao F.S., Chen C., Song C. \& Zeng F., 2014, Recent progress in resistive random access memories: materials , switching mechanisms and performance, Material Science. Engineering, Vol. 83, pp. 1-59, DOI:10.1016/j-mser.2014.06.002

Philipwong H.S., Raoux S., Kim S., Liang J., 2010, Phase Change Memory, IEEE, Vol. 98. DOI:10.1109/JPROC.2010.2070050

Raoux, S. \&Wuttig, M. (eds), 2012, Density- Functional theory guided advances in phase change materials and memories, MRS Bulletin, Vol. 37. DOI:10.1557/mrs.2015.227

Raoux S., Welnic W., Ielmini D., 2009, Phase Change materials and their application to non volatile memories, ACS Publication, Vol 110, pp. 240-267. DOI:10.1021/cr900040x

Raoux S., Xiong F., Wuttig M., Pop E., 2014, Phase Change Materials and phase change memory, MRS Bulletin, Vol 39, p. 708. DOI:10.1557/mrs.2014.139

Rao V., Mehta N., Dwivedi D.K., 2017, Investigations of crystallization kinetics of $\operatorname{Se}_{82-\mathrm{x}} \operatorname{Te}_{18} \mathrm{Sb}_{\mathrm{x}}(\mathrm{x}=0,4,8,12$ at \%) glassy alloys, Material Research Innovation, Vol. 34, pp. 3-7

Rao V. and Dwivedi D.K, 2017, Glass transition kinetics and thermal stability of $\mathrm{Se}_{82-\mathrm{x}} \mathrm{Te}_{18} \mathrm{Sb}_{\mathrm{x}}(\mathrm{x}=0,4,8$ and 12 at \%) glassy alloys, Journal of Material Science, Vol. 10, No. 29, pp. 1-2.

Rao V. and Dwivedi D.K, 2017, Phase Change Chalcogenide materials for optical data structure, Journal of Material Science, Vol. 28, pp. 6208-6216.

Shaikh S., Lafdi K., Hallinan K. P. 2008, Carbon nanoadditives to enhance latent energy storage of phase change materials, Journal of Applied Physics, Vol. 103, 094302. DOI:10.1063/1.2903538

Simpson, R.E.et., Interfacial Phase Change Memory, Nature Nanotechnology,Vol 10,414-419(2010).DOI:10.1038/nnano.2011.96

Singh P.K., Dwivedi D.K., 2017, Chalogenide glass:Fabrication Techniques, properties and applications, Ferroelectronics, Vol. 520, pp. 256-273, DOI:10.1080/00150193.2017.1412187

Vial, G., 2005, Different databases for different strokes, MRS Bulletin, Vol. 35, No. 2, pp. 80-85. DOI: 10.1109/ms.2018.1661308

Wuttig, M., Phase Change Materials: Towards an Universal memory, Nature Materials, Vol. 4, pp. 265-266. DOI:/10.1038/nmat1359 
Yang, T.-Y., Park, I.-M., Kim, B.-J. \&Joo, Y.-C., 2009, Atomic migration in molten and crystalline $\mathrm{Ge}_{2} \mathrm{Sb}_{2} \mathrm{Te}_{5}$ under high electric field, Applied Physics Letters, Vol 95, 032104. DOI:10.1063/1.3184584

Yamada N., E. Ohno, N. Akahira, K.Nishiuchi, K. Nagata, 1987, High speed overwritable phase change optical disk material, Japanese Journal of Applied Physics, Vol. 26, pp. 61-66. DOI:10.7567/JJAPS.26S4.61

\section{Biographical notes}

Pooja Gupta and D.K. Dwivedi are of the Department of Physics and Material Science, Madan Mohan Malaviya University of Technology, India while Pooja Lohia belongs to the Department of Electronics and communication, Madan Mohan Malaviya University of Technology, India 